\title{
Điểm tin RW Weekend Read ngày 16-1-2021
}

AISDL

January 17, 2021

Bản Weekend Read của RetractionWatch ngày 16-1 có tựa đề: Pollution of COVID-19 research; climate papers lead to reassignment; time to publish less?

AISDL điểm vài sự kiện trong bản tin cuối tuần như sau:

- "Khoảnh khắc kinh hoàng trong sự nghiệp." Làm gì khi chợt nhận ra bao năm tạo dựng kết quả nghiên cứu của bản thân đã dựa trên một kết quả/phương pháp sai lầm? Sự kiện này liên quan tới bài trên Science Signaling bị rút: https://stke.sciencemag.org/content/9/423/ra36 [2]

- Nhà vật lý Šorli có bài trên Scientific Reports bị rút. Ông hỏi xin danh tính người chỉ trích sai lầm của bài để liên lạc để trao đổi: "Tranh cãi trực tiếp là một thành tố quan trọng của quá trình tiến bộ ngành vật lý." Tuy nhiên, ban biên tập tạp chí đã từ chối yêu cầu này [3]

- Tạp chí PLoS ONE ra cảnh báo với một bài nghiên cứu của các tác giả Hàn Quốc trong năm 2020 về sử dụng in 3-D để làm mắt giả cho chó. Lập luận: “Khó có thể tìm được lý do đúng đắn cho việc tiến hành các nghiên cứu loại này" [4]

Tính đến hết tuần 16-1, RW cũng đã thống kê được 75 bài nghiên cứu về COVID-19 đã bị rút khỏi các ấn phẩm (xem chi tiết: https://retractionwatch.com/retracted-coronavirus-covid-19-papers/).

Đặc biệt hơn là hai vấn đề có liên quan trực tiếp tới các bài bị rút:

- "Nhiều nhà khoa học trích dẫn đội bài COVID-19 bê bối lời đi thực tế chúng bị rút." [5]

- "Các nghiên cứu COVID-19 bị rút và mức độ "ô nhiễm trích dẫn": nghiên cứu sơ khởi và các hướng nghiên cứu tiếp theo." [6]

Hai vấn đề vừa nêu trên có liên quan trực tiếp tới quan điểm về cataloging thông tin thành cơ sở dữ liệu đối với việc rút bài và lưu trữ của hệ thống biên tập toàn cầu [7]. Kể từ khi quan điểm này được xuất bản, tình hình rút bài ngày càng nghiêm trọng hơn, và hướng xử lý thông tin vẫn chưa có tiến triển trong hệ thống xuất bản toàn cầu. Thông tin bài rút trên RW ngày một dầy đặc hơn.

\section{References}

[1] RW. (2021). Weekend reads: Pollution of COVID-19 research; climate papers lead to reassignment; time to publish less?. RetractionWatch (January 16). https://retractionwatch.com/2021/01/16/weekend-reads-pollution-of-covid-19-researchclimate-papers-lead-to-reassignment-time-to-publish-less/ 
[2] Coleman, J. L., Ngo, T., Schmidt, J., Mrad, N., Liew, C. K., Jones, N. M., ... \& Smith, N. J. (2016). Metalloprotease cleavage of the $\mathrm{N}$ terminus of the orphan $\mathrm{G}$ protein-coupled receptor GPR37L1 reduces its constitutive activity. Science Signaling, 9(423), ra36-ra36.

[3] Šorli, A. S. (2019). Mass-Energy Equivalence Extension onto a Superfluid Quantum Vacuum. Scientific Reports, 9(1), 11737.

[4] Park, S. Y., An, J. H., Kwon, H., Choi, S. Y., Lim, K. Y., Kwak, H. H., ... \& Park, K. M. (2020). Custommade artificial eyes using 3D printing for dogs: A preliminary study. PloS one, 15(11), e0242274.

[5] Piller, C. (2021). Many scientists citing two scandalous COVID-19 papers ignore their retractions. Science (Jan. 15); doi:10.1126/science.abg5806.

[6] Van Der Walt, W., et al. (2021). Retracted COVID-19 papers and the levels of 'Citation Pollution': A preliminary analysis and directions for further research. Cahiers de la Documentation - 2020/3-4. http://vital.seals.ac.za:8080/vital/access/manager/PdfViewer/vital:41508/SOURCE1?viewPdfInt ernal=1

[7] Vuong, Q. H. (2020). Reform retractions to make them more transparent. Nature, 582(7811), 149. 